\title{
Software with a graphical interface for design optimization of prestressed concrete launched bridges
}

\author{
A. N. Fontán, S. Hernández \& F. J. Tsao \\ School of Civil Engineering, University of A Coruña, Spain
}

\begin{abstract}
A computer code aimed to produce optimum design of prestressed concrete launched bridges during construction phase is presented in this paper. The software provides the least cost design for a prestressed concrete bridge constructed by incrementally launching procedures, searching simultaneously for the optimum cross-section dimensions and the prestressing forces of the concrete deck, as well as the most adequate characteristics of the launching nose. The code incorporates the complete set of constraints considered in the Spanish code of practice for this type of structure. The software features an advanced graphical interface to provide a user friendly communication. This graphical environment allows managing multiple projects simultaneously. The benefit of considering the numerical optimization instead of design rules, established by well known bridge designers that can be found in the literature, has been demonstrated by authors in previous publications. In this paper an application example is presented to make clear the capabilities of the code.

Keywords: structural optimization, structural design, incrementally launched bridges, concrete bridges, launching nose.
\end{abstract}

\section{Introduction}

The Incrementally Launching Method (ILM) is a common construction procedure for medium span prestressed concrete bridges that consist of building a deck by segments on the ground and advancing the already-built deck portion periodically over the piers until reaching its final position in a similar way to an extrusion [1-4]. 
Incrementally launched bridges base their economical advantages on not requiring falsework to support the deck during their construction, although a series of auxiliary elements are required: a casting yard, launching devices and a launching nose, which is a light structure normally made of steel, attached ahead of the front part of the deck as an extension allowing to reduce the stresses produced in the cantilever configuration of the concrete girder during launch.

Also, during the construction of a concrete launched bridge it is necessary to consider a prestressing force without eccentricity, known as centric prestressing. The objective of this active reinforcement is to limit at the same time the tensile stresses at the top and bottom extreme fibres of the deck, since due to the launching process, any cross-section will have to support both positive and negative bending moments during launch, while passing over a support or the middle of a span.

Surprisingly, the design of launched bridges is usually carried out by trial and error.

\section{Optimization of launched bridges}

Several strategies can be followed to improve the construction process of an incrementally launched prestressed concrete bridge. The first alternative is to use traditional methods to design the launching nose, but does not guarantee the best possible solution. Another possibility is to use more sophisticated and powerful methods, using mathematical optimization tools to determine the best dimensions of the launching nose, the deck cross-section and the centric prestressing forces.

The conventional design method basically consists of modifying an initial design by trial and error until a final design is satisfying enough. This process of trial and error does not guarantee achieving the best possible solution and is necessarily limited to a low number of trials. The conventional methods have been used by several authors [5-8] to improve the design of the launching nose and obtain the minimum bending moment in the deck.

A first approach to optimize the launching nose of a launched bridge is to use a parametric model and assume as the optimal length of the launching nose that minimizes the maximum stresses in the deck $[9,10]$. Using this approach shows that certain assumptions for the conventional design procedure are not justified. Furthermore, the use of trial and error methods may lead sometimes to error and produce inaccurate results. In any case, it is necessary to consider adequate relations between nose and deck for the results of a parametric optimization of the launching nose to be feasible.

To avoid the limitations of the conventional method or parametric models it is necessary to consider a more general methodology to optimize the construction of a prestressed concrete launched bridge.

This research work proposes a global optimization strategy, solving a structural model for both the nose and deck that simulates the entire launching process and considers the actual geometrical and mechanical characteristics of 
the deck and the launching nose, using practical design criteria and taking into account the real problems that engineers usually find.

With this new formulation, the optimization of a launched bridge is not limited to improve the launching nose design, but extended to obtain at the same time the more appropriate values of the dimensions of the deck cross-section, the launching nose and centric prestressing forces to minimize the total cost of the nose and deck. This paper presents the computer application vPULO so that this approach is feasible in terms of time and resources consumption.

This code allows us to generate the structural models of the continuous beam (nose-deck set) for each instant during launch, to analyze the worst internal forces during the construction using matrix analysis and to perform the iterations needed by the optimization algorithms to obtain the optimum launched bridge in terms of construction costs. The code is managed through a friendly graphical user interface to input data and output results.

\section{Description of the software vPULO}

vPULO code is organized into blocks shown in the flowchart of Figure 1, which in turn are divided into other modules, responsible for solving specific tasks.

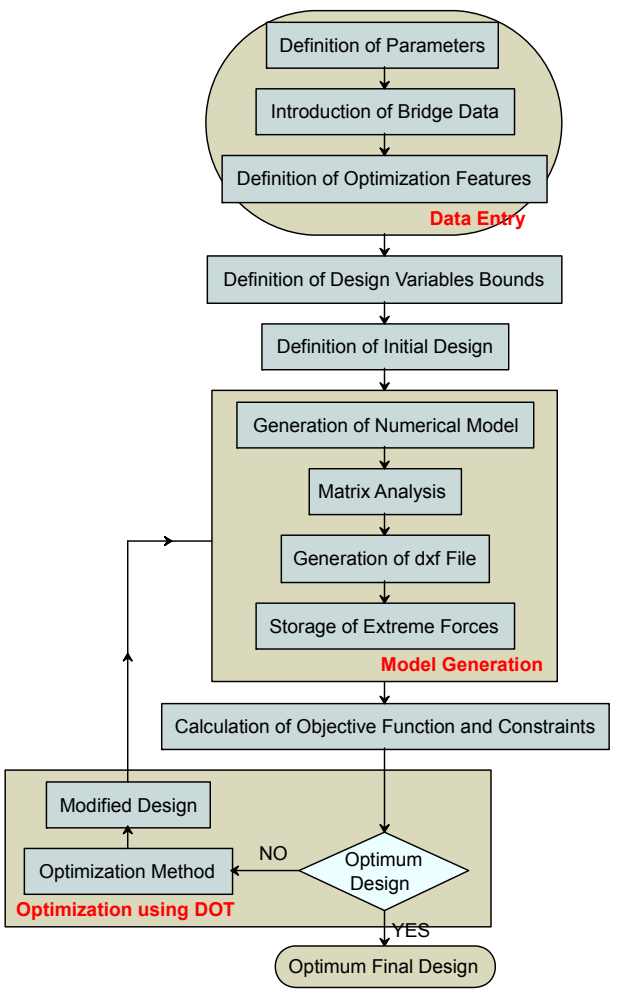

Figure 1: $\quad$ Flowchart of the program vPULO. 
The general characteristics and the initial design of the prestressed concrete launched bridge are defined in the first block. The second block is responsible for generating and analyzing all structural models to be considered during the launching process. Finally, the third block deals with optimization tasks using the commercial code DOT [11].

The calculation engine has been developed in Fortran 77, by calling the DOT functions for the optimization process. The graphical environment for pre and post-processing has been made by an object-oriented development in $\mathrm{C}++$ with free programming libraries, Qt for window management, and Qwt for insertion and manipulation of graphics post-processing.

\subsection{Model definition}

The distribution of bridge spans is constant with length $L$, except for the end spans with $k \cdot L$.

The bridge deck has a constant height $H$ and hollow box cross-section with flanges, where top and bottom slabs and two inclined webs have constant thickness, respectively $e_{s}, e_{i}, e_{a}$ (Figure 2).

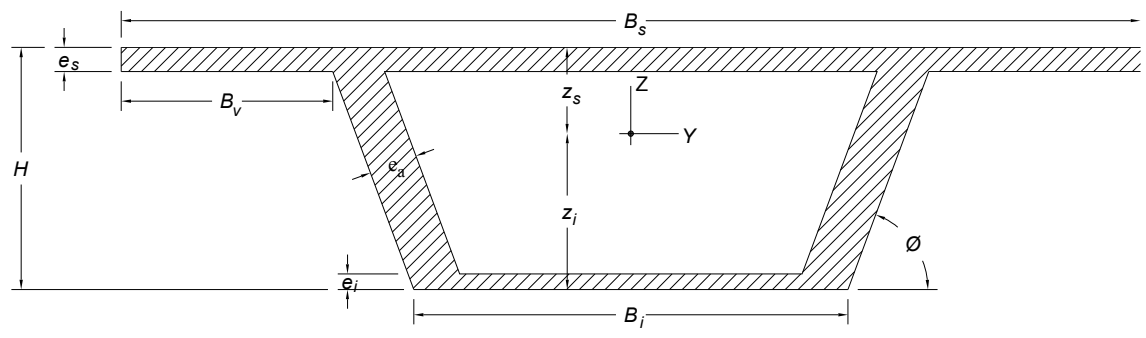

Figure 2: Box cross-section with flanges.

In order to control the stresses in the front end of the deck, a launching nose is considered to be made up with a pair of reinforced beams with solid web and variable height (Figure 3). Both of them are I-beams with constant thickness and linearly variable web height. At the joint with the deck, the launching nose has the same height as that of the deck $H$, while at the front end, its height es $h_{N}$. The two beams of the launching nose must be strongly stiffened and braced between them to avoid any instability. Neither stayed front system nor temporally piers are considered.

For the launching of the concrete girder, a centred straight constant prestressing is needed, that produces only axial compression on the beam. Because bending forces are bigger at the front end of the deck than the rest, a larger centric prestressing $\left(P_{f}\right.$, frontal centric prestressing) is used for the first segments than for the rest of the bridge ( $P_{d}$, dorsal centric prestressing). The designer must define the number of the foremost segments with larger prestressing. 

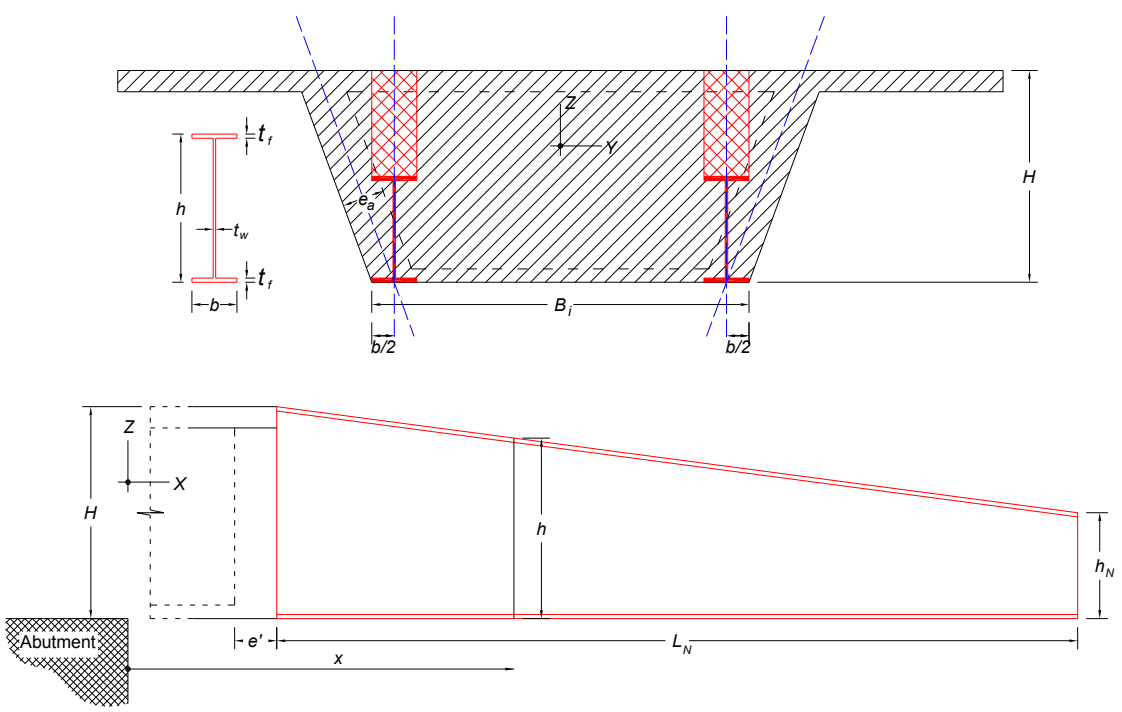

Figure 3: Cross-section and side view of a generic launching nose.

The most appropriate segment length is one half of the regular span (Figure 4). The segments of the end spans have different length.

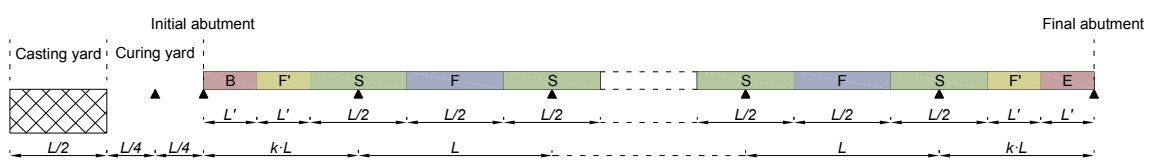

Figure 4: $\quad$ Supports of the structural model.

After defining all the supports and segment sizes for the deck, all the intermediate configurations and sectional forces for the nose-deck system during launch can be determined precisely.

In the model, the considered loads during the construction phase are the selfweight of the deck and the diaphragm of the nose-deck joint, the centric prestressing, thermal gradients and a possible overload acting uniformly on the full length of the girder. According to the Spanish construction codes [12], the following criteria must be satisfied for the calculation of the prestressed concrete bridge deck:

- dimensioning the deck for limit state of decompression,

- dimensioning the web for limit state of shear,

- checking the cross-section for limit state of bending and longitudinal forces,

- checking the deck for serviceability limit state of deformation.

Therefore, the limit states of decompression and shear are taken into account for dimensioning. For a later study, it will be necessary to define passive reinforcement and parabolic prestressing to suit the above requirements. 
Taking into account an intense level of execution control, due to a semiindustrial production, and considering the partial safety factors for the loads during transitory stage (construction phase), it is possible to calculate all the required load combinations. Only eight load combinations are necessary to obtain the worst sectional forces for the previously mentioned limit states.

\subsection{Numerical model generation and analysis}

During the construction process, from the time when the launching nose is placed on the sliding area and the first deck segment is concreted, until the complete girder reaches its final position and the launching nose is removed, the nose-deck system goes through an infinite number of different static configurations.

In order to obtain the maximum forces that the deck experiences during this process, it is necessary to solve a numerical model of the nose-deck system in the worst configurations. To simulate the complete constructive process of a launched bridge, a specific computer code was created, which generates numerical models for all the representative situations during the launching phase.

Later, these models are calculated with an original matrix structural analysis module based in linear elastic theory and that considers variable cross-section. This software solves sectional forces adequately considering the contribution of the launching nose to the behaviour of the nose-deck system by evaluating correctly the inertial variation of the nose.

\subsection{Formulation of the optimization problem}

The proposed formulation considers that the objective function is the sum of the total construction cost of the concrete deck, the cost of launching nose, and the cost of the centric prestressing.

The design variables, characteristics of the problem that can be varied during the optimization process, are the dimensions of cross-section of the concrete deck, the size of the launching nose, and the value of centric prestressing forces in the front and back part of the girder, namely:

1. $H$ : height of the concrete deck.

2. $e_{s}$ : thickness of the top slab of the deck cross-section.

3. $e_{i}$ : thickness of the bottom slab of the deck cross-section.

4. $e_{a}$ : thickness of the inclined webs of the deck cross-section.

5. $h_{N}$ : height of the launching nose at its fore end.

6. $L_{N}$ : length of the launching nose.

7. $t_{f}$ : thickness of the flanges of the launching nose.

8. $t_{w}$ : thickness of the webs of the launching nose.

9. $P_{D}$ : prestressing force in the rear part of the deck.

10. $P_{F}$ : prestressing force in the front part of the deck.

The limits of validity and a starting value of each design variable can be established using technical criteria and experience from similar previous works [1-3]. 
The optimization constraints limit the stresses in the deck and the launching nose.

To satisfy the serviceability limit state (SLS) of decompression in the concrete deck, tensile stresses cannot be produced neither in the topmost or bottommost fibre of the cross-section for the maximum and minimum bending moment of SLS. Moreover, the compressive stresses should be limited in order to avoid cracks by excessive compression in concrete.

To fulfil the ultimate limit state (ULS) of shear in the webs of the concrete deck cross-section, it is necessary to check if the maximum shear force will not exceed the shear strength of the webs by both oblique compression and tension.

The steel launching nose is dimensioned according to Eurocode 3 [13] by limiting the worst normal and shear stresses for ULS. Notice that the crosssection is variable.

The worst case forces are calculated for the 8 load combinations, distinguishing between the front and back segments of the deck. Similarly, the worst section forces are obtained for the launching nose. Considering all of the above, 14 different optimization constraints are generated.

Thus, the optimization of a launched bridge results in a problem with 10 design variables and 14 constraints, which can be considered to be a mediumsize problem, however, it is highly nonlinear for its objective function as well as constraints. Therefore, it should be resolved by numerical methods $[14,15]$ and computer applications [11]. Three different optimization algorithms were employed:

- Method 1: modified method of feasible directions.

- Method 2: sequence of linear problems.

- Method 3: sequence of quadratic problems.

The internal parameters of DOT are totally configurable such as the tolerances to satisfy the constraints, the maximum absolute or relative change of the objective function between a certain number of successive iterations to show convergence, or the maximum step for the derivates calculations for finite difference method. Gradients can be calculated by first forward or central finite difference, which is more accurate, but the number of function evaluations is almost doubled.

\subsection{Graphical user interface}

A graphical user interface (GUI) has been developed to interact friendly with the calculation core. This graphical environment controls the entire program, both pre and post-processing, i.e. for data entry and presentation of results.

An important feature of the code is that it can process several independent models at the same time. This is necessary because the calculation process can be long depending on the size of the model and the hardware. It is possible to run several problems at once, to compare results of models already solved or simply to display results of an example while the program calculates a different one. The user is informed when the optimization algorithm reaches the convergence. 
This GUI has all the usual functionalities in a computer program with windows and menus. In the main window are two tabs: "Projects" and "Results". For multiple projects running at a given time, the first tab manages the data entry and the second the obtained results.

\section{Application example}

An example of a launched bridge is solved to demonstrate the operation and benefits of the program. The model has total length of $510.4 \mathrm{~m}$ divided into 12 spans as the distribution shown in Figure 5. The rest of the parameters are:

- cross-section: $B_{s}=12 m, B_{i}=5 m, B_{v}=3 m$,

- number of deck segments with front prestressing: 4 ,

- launching nose: steel $S 275,15 \%$ additional weight due to bracing and stiffening,

- materials: reinforced concrete $H A 50$, passive steel $B 500 S$, active steel $Y 1770$,

- thermal loads: $\Delta T=-3{ }^{\circ} \mathrm{C}, \Delta T^{+}=7{ }^{\circ} \mathrm{C}$,

- prices: $P_{\text {steel }}=2 € / \mathrm{kg}, P_{\text {prestressed steel }}=3.1 € / \mathrm{kg}, P_{\text {concrete }}=90 € / \mathrm{m}^{3}$.

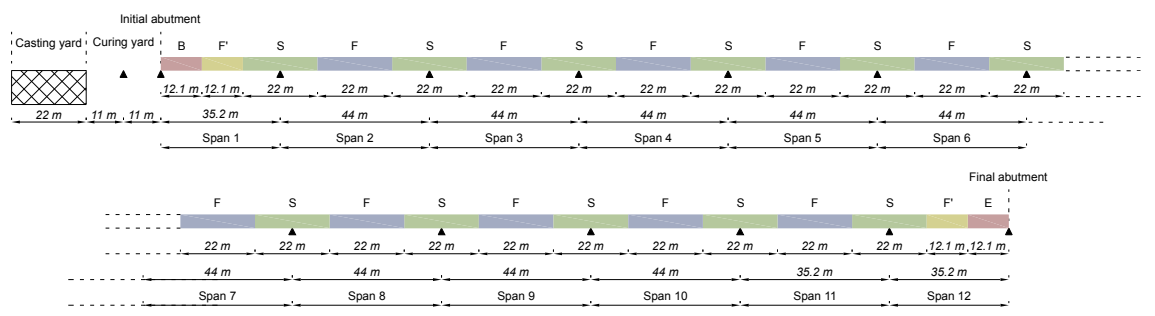

Figure 5: $\quad$ Span distribution of the bridge model.

The initial values of the design variables are: $\mathrm{H}=3.2 \mathrm{~m}, \mathrm{e}_{\mathrm{s}}=25 \mathrm{~cm}, \mathrm{e}_{\mathrm{i}}=25$ $\mathrm{cm}, \mathrm{e}_{\mathrm{a}}=47 \mathrm{~cm}, \mathrm{~L}_{\mathrm{N}}=26.4 \mathrm{~m}, \mathrm{~h}_{\mathrm{N}}=1 \mathrm{~m}, \mathrm{t}_{\mathrm{f}}=2 \mathrm{~cm}, \mathrm{t}_{\mathrm{w}}=1.5 \mathrm{~cm}, \mathrm{P}_{\mathrm{F}}=45 \mathrm{MN}$, $\mathrm{P}_{\mathrm{D}}=35 \mathrm{MN}$.

The first step is create a new model from the File menu, and then, in the main form the model data are inserted in different windows: "Viaduct geometry, longitudinal and transversal" (Figure 6), "Launching nose geometry" (Figure 7), "Features of reinforcement", "Features of materials", "Loads and construction procedure", "Materials prices".

After entering the model data it is possible to start the analysis. First of all, the code checks data for errors. Then, a form is shown for entering the optimization parameters of DOT code and finally the calculation is started (Figure 8).

To view and analyze the results of the optimization process, the user must open the tab "Results" in the main window, from where are available the following forms:

- Main results (Figure 9). The optimum design and the achieved construction cost improvement during the optimization are shown. 
- Optimization process (Figure 10). Graphics of the evolution of the objective function, design variables and constraints during the optimization process are drawn.

- Original project. Initial values of the model before optimization are listed.

- Optimization parameters. Parameters used by optimization algorithms are showed.

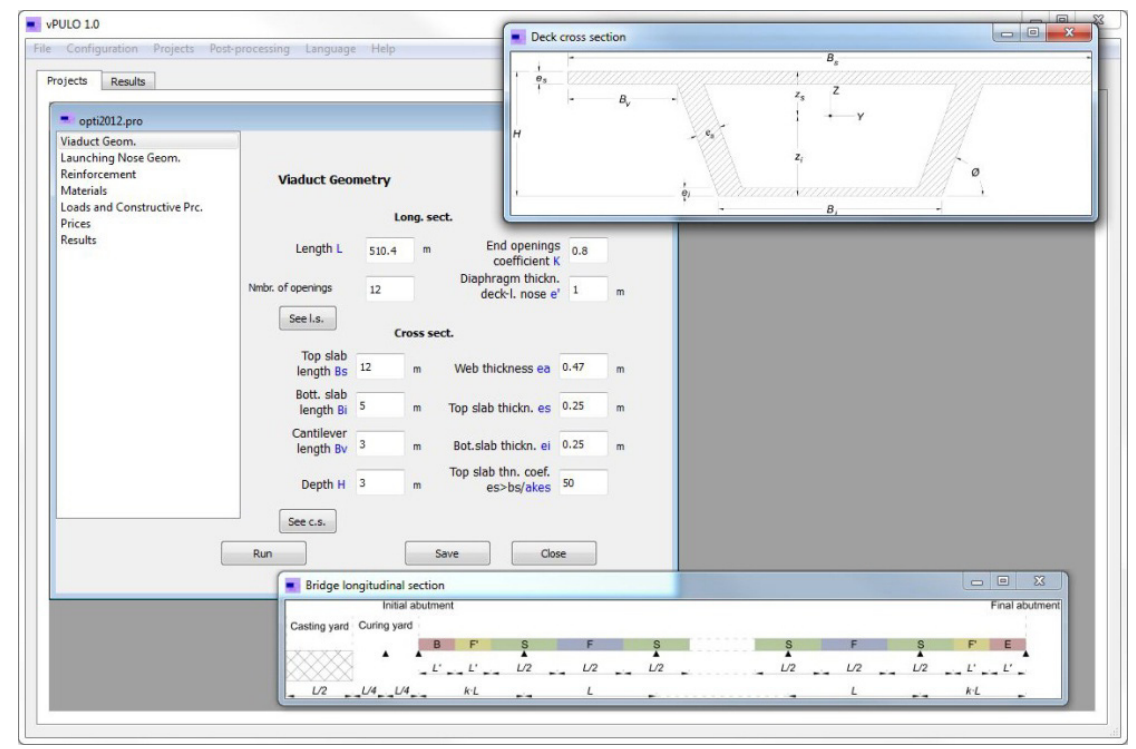

Figure 6: Form of viaduct geometry, longitudinal and transversal.

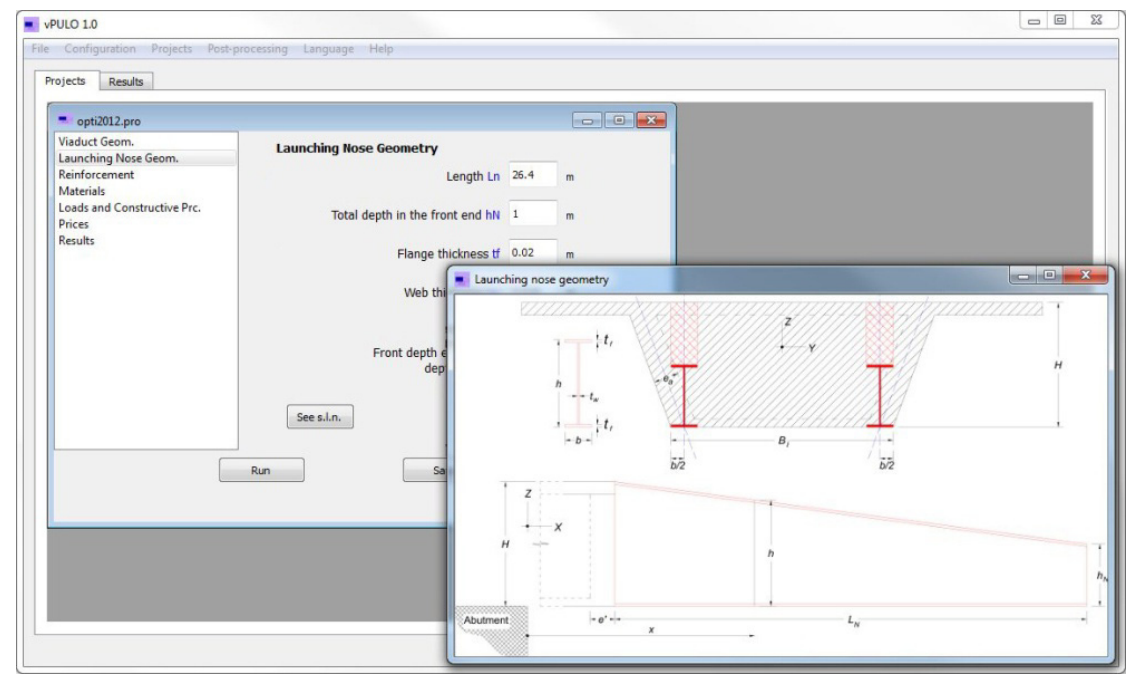

Figure 7: Launching nose geometry form. 


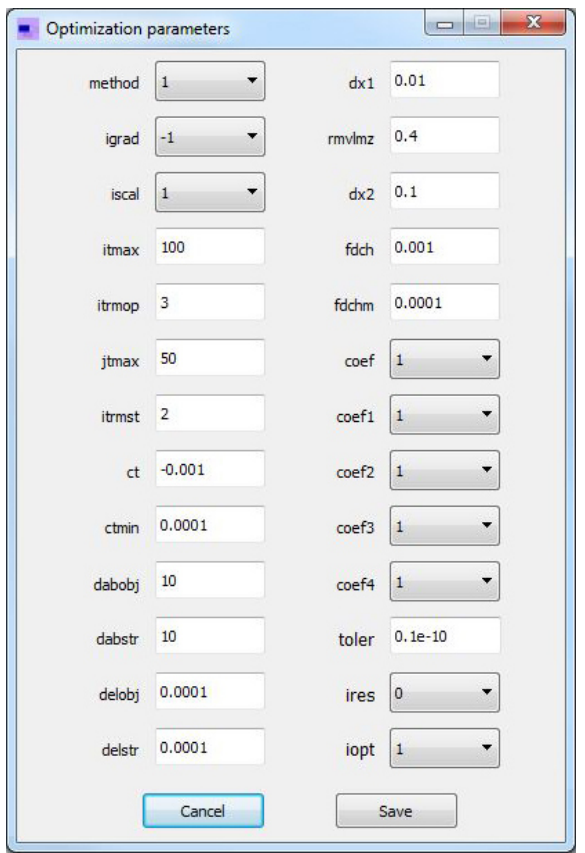

Figure 8: Window of optimization parameters.

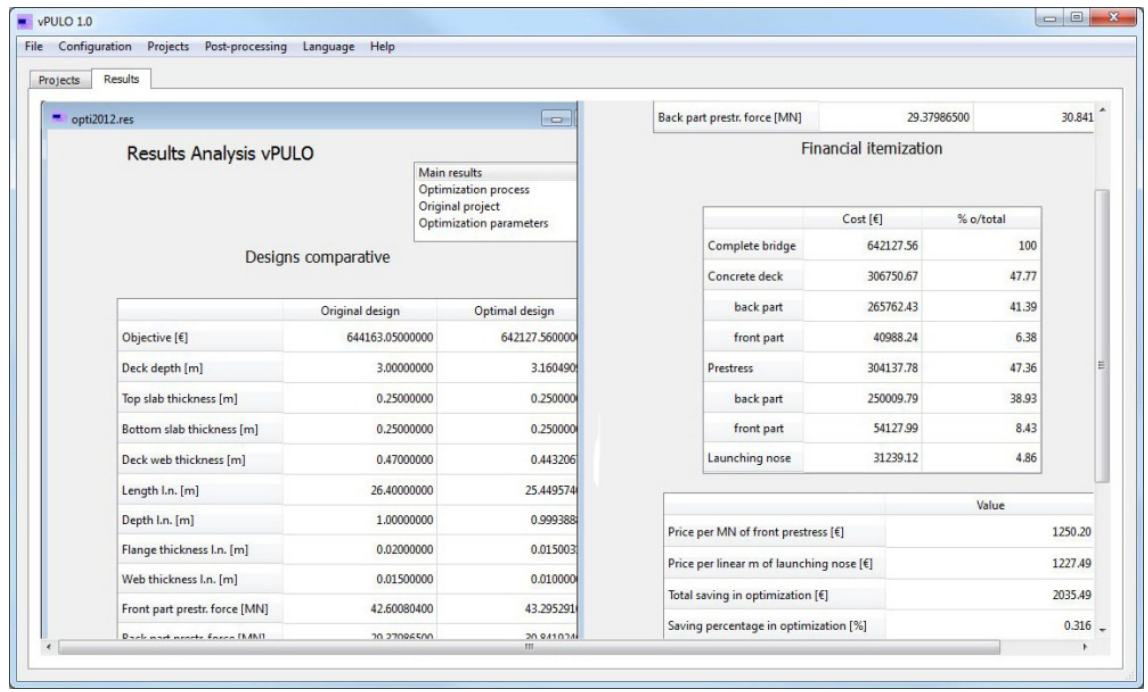

Figure 9: Main results. 


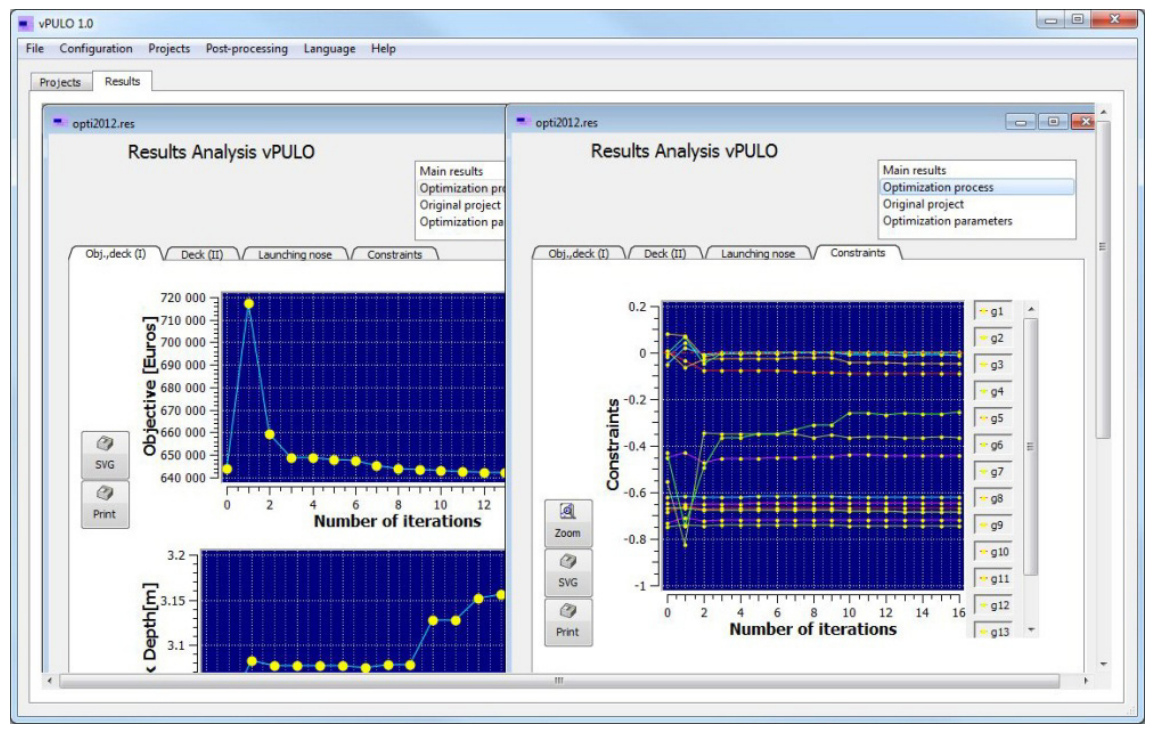

Figure 10: Evolution of objective function, design variables and constraints.

\section{Conclusions}

This article presents the simultaneous optimization of the deck cross-section, the centric prestressing forces, and the launching nose of prestressed concrete launched bridges, using software with graphical user interface. The main conclusions are the followings:

- The present techniques for dimensioning of launching noses are based on trial and error methods. Therefore, they are inaccurate and can lead to an error.

- Launched bridges are a suitable case for application of structural optimization methodologies that can overcome the limitations of conventional design methods.

- The optimization of a launched bridge requires searching simultaneously for the most appropriate dimension values of the launching nose and the deck cross-section as well as the centric prestressing forces so that the total construction cost of deck-nose system will be minimum, with the required codes satisfied.

- The application of numerical techniques to the optimization of launched bridge construction allows designers to take better decisions.

- User friendly software can help in introducing new design techniques. The software vPULO, with its graphical user interface makes it easy to obtain the optimal solution to the problem studied. 


\section{References}

[1] Bouchon, E. and et al., Guide des ponts poussés, Association français de genie civil, Presses de l'ecole nationale des ponts et chausées, 1999.

[2] Göhler, B. and Pearson, B., Incrementally launched bridges: Design and construction, Wiley, New York, 2000.

[3] Rosignoli, M., Bridge launching, Thomas Telford, 2002.

[4] AASHTO, Bridge construction practices using incremental launching, American Association of State Highway and Transportation Officials, Highway Subcommittee on Bridge and Structures, 2007.

[5] Iglesias, C., Algunas ideas sobre el predimensionamiento de puentes empujados, Hormigón y Acero, Vol. 182, pp.111-128, 1992.

[6] Rosignoli, M., Nose-deck interaction in launched prestressed concrete bridges, J. Bridge Eng., Vol. 3 (1), pp.17-21, 1998.

[7] Choi, H.Y., Suh, S.K., Oh, M.S. and Oh, S.H., Techniques of optimizing the launching nose in incremental launching method, The $5^{\text {th }}$ international symposium on steel structures, Seoul, South Corea, pp.954-961, 2009.

[8] Wang, W., Zheng, H. and Zeng, X., Optimum design of launching nose during incremental launching construction of same-span continuous bridge, World Academy of Science, Engineering and Tech., 72, 2010.

[9] Fontán, A.N., Optimización de la sección transversal y del pico de lanzamiento de puentes lanzados de hormigón pretensado, Doctoral Thesis, University of A Coruña, 2009.

[10] Fontán, A.N., Hernández, S., Baldomir, A. and Díaz, J.M., Diseño óptimo del pico de lanzamiento de puentes lanzados de hormigón pretensado, Rev. Int. Metod. Numer. Calc. Dise., Vol. 28 (2), 2012.

[11] DOT, DOT Design Optimization Tools. User Manual. Version 5.0, Vanderplaats Research and Development, Inc., 2001.

[12] EHE, Instrucción de hormigón estructural, Comisión permanente del hormigón, Ministerio de Fomento, Spain, 2008.

[13] Eurocódigo 3, Proyecto de estructuras de acero, AENOR, 2008.

[14] Hernández, S., Métodos de diseño óptimo de estructuras, Colegio de ingenieros de caminos, canales y puertos, 1990.

[15] Vanderplaats, G.N., Numerical optimization techniques for engineering design: with applications, $3^{\mathrm{a}}$ edition, Vanderplaats Research and Development, inc., Colorado Springs, 2001. 